\title{
Financiamento Empresarial de Campanhas Eleitorais: Análise Empírica dos Desdobramentos Após Julgamento da Ação Direta de Insconstitucionalidade Pelo STF
}

\author{
Lilian Balmant Emerique \\ Pós-doutora em Ciências Jurídico-políticas, doutora e \\ mestre em Direito e em Ciência Política e Relações Inter- \\ nacionais. Pesquisadora na área do Direito e da Ciência \\ Política. Professora-adjunta da Faculdade de Direito e do \\ Programa de Pós-Graduação em Direito da Universidade \\ Federal do Rio de Janeiro. lilamarcia@gmail.com
}

\section{Eduardo Morrot Coelho Madureira}

Bacharel em Direito e ex-bolsista de extensão Proext pela Universidade Federal do Rio de Janeiro. madureira. morrot@gmail.com

\section{Resumo}

0 presente estudo tem como objetivo analisar o processo da Ação Direta de Inconstitucionalidade n. 4.650/2011 no Supremo Tribunal Federal, que avaliou o financiamento empresarial das campanhas eleitorais por meio dos seus atores e de um exame empírico sobre seus efeitos nas eleições à Prefeitura do Rio de Janeiro em 2016. De início, tratamos do enquadramento teórico no contexto do constitucionalismo democrático (POST; SIEGEL, 2013) sobre o papel da Corte e dos movimentos e sociedade civil no processo de interpretação constitucional. Em seguida, observamos a trajetória da luta dos movimentos sociais pela reforma política com seus avanços e estagnações. Passamos, então, à apreciação do debate no STF e, por fim, efetuamos diagnóstico das mudanças e de suas insuficiências em matéria eleitoral. Metodologia - Pesquisa teórica e empírica: levantamento e análise dos dados de sites de acompanhamento das prestações de contas e aspectos relativos às eleições no município do Rio de Janeiro nos anos de 2012 e 2016. Resultados obtidos do julgamento denotam uma busca por um constitucionalismo democrático, em que a legitimidade flui de baixo para cima. 
Assim, o processo ilustra como os tribunais refletem, mas também constroem, a opinião pública. Após a decisão do STF de proibir o financiamento empresarial de campanhas é possível notar, ao menos nas eleições à Prefeitura do Rio de Janeiro, uma relação correlata de redução do montante total dos recursos, menor desigualdade entre os candidatos e maior peso de pequenas doações individuais nas campanhas.

Palavras-chave: Financiamento eleitoral. Constitucionalismo democrático. Movimentos sociais. Interpretação constitucional. Controle de constitucionalidade.

\title{
Business Financing of Electoral Campaigns: Empirical Analysis Abaut Developments After Judicial Review Action
}

\begin{abstract}
The present study aims to analyze the process of ADI 4.650/2011 in the Brazilian Supreme Court, which analyzed the financing of electoral campaigns through empirical examinations on its effects on the elections for Rio de Janeiro City Mayor in 2016. At the outset, we deal with the theoretical framework in the context of Democratic Constitutionalism (Post and Siegel) on the role of the Supreme Court, social movements and civil society in the process of constitutional interpretation. Next, we observe the trajectory of the social struggle for the political reform with its advances and stagnations. We then proceeded to evaluate the Supreme Court debate and, finally, make a diagnosis of the changes and their electoral insufficiency. Methodology: analysis of data from websites to monitor the rendering of accounts and aspects related to the elections in the municipality of Rio de Janeiro in the years 2012 and 2016. Results obtained from the trial denote a search for a democratic constitutionalism, where legitimacy flows from the bottom up. Thus, the process illustrates how the courts reflect, but also build public opinion. After the decision of the STF to prohibit the corporate financing of campaigns, it is possible to note, at least in the elections to the city of Rio de Janeiro, a correlative relation of reduction of the total amount of resources, less inequality between the candidates and greater weight of small individual donations Campaigns.
\end{abstract}

Keywords: Electoral financing. Democratic constitucionalism. Social movements. Constitutional interpretation. Judicial review.

Recebido em: 9/6/2017

Aprovado em: 25/9/2017

\section{Sumário}

1 Introdução. 2 Constitucionalismo democrático (POST; SIEGEL): Povo e Corte, unir aos separados. 3 Demanda social pela reforma política: o problema do financiamento empresarial de campanhas e as tentativas frustradas de reformas políticas. 4 Argumentos jurídicos sobre a inconstitucionalidade do financiamento empresarial de campanhas políticas. 50 que mudou? Análise empírica do financiamento nas campanhas eleitorais para a Prefeitura do Rio de Janeiro em 2012 e 2016. 6 Conclusão. 7 Referências. 


\section{INTRODUÇÃO}

O debate sobre o financiamento das campanhas eleitorais é central para compreendermos fragilidades da nossa democracia. A influência do poder econômico nas eleições é uma grave fonte de distorção e intervenção de empresas privadas nos processos políticos, gerando resultados nos quais a maioria dos representantes eleitos são aqueles que obtiveram maior financiamento empresarial. Após as eleições, esses representantes prestam contas às empresas financiadoras, não ao povo que os elegeu. Segundo dados da Organização Não Governamental (ONG) "Transparência Brasil”, dos 513 deputados federais eleitos em 2010, o número expressivo de 320 eram financiados pelas grandes empresas doadoras. ${ }^{1}$

A Constituição de 1988 aborda esse tema, prevendo a regulamentação por uma lei complementar em seu artigo $14^{\circ}, \S 9^{\circ} .^{2}$ Apesar, no entanto, de prever a sua regulamentação, as campanhas eleitorais no Brasil continuavam a ficar cada ano mais caras e a influência do poder econômico era a regra sobre os candidatos eleitos.

Em setembro de 2011, o Conselho Federal da Ordem dos Advogados do Brasil (CFOAB) deu entrada no Supremo Tribunal Federal (STF) com uma Ação Direta de Inconstitucionalidade (ADI) sobre o financiamento empresarial de campanhas eleitorais. Depois das grandes manifestações que lotaram as ruas em junho de 2013, a enorme crise de

\footnotetext{
${ }^{1}$ ABRAMO, Cláudio Werner. Poder econômico e financiamento eleitoral no Brasil - Parte 2: concentração e efetividade das doações privadas. p. 3-8. Disponível em: <excelencias.org. br/docs/financia_desigualdade.pdf $>$ Acesso em: 7 maio 2017.

${ }^{2}$ Artigo 14, § 9º da Constituição da República Federativa do Brasil de 1988: Lei complementar estabelecerá outros casos de inelegibilidade e os prazos de sua cessação, a fim de proteger a probidade administrativa, a moralidade para exercício de mandato considerada vida pregressa do candidato, e a normalidade e legitimidade das eleições contra a influência do poder econômico ou o abuso do exercício de função, cargo ou emprego na administração direta ou indireta.
} 
representatividade em nossa sociedade e as inúmeras tentativas frustradas de reformar o sistema político brasileiro, uma série de entidades se incorporaram, enquanto amicus curie, e o processo ganhou relevância nacional.

Em abril de 2014 iniciou-se a votação e seis ministros votaram a favor da inconstitucionalidade da doação de empresas às campanhas eleitorais. Apesar de já constituída maioria, o ministro Gilmar Mendes pediu vista e travou o processo por mais de um ano - a despeito de intensas manifestações da sociedade civil pelo seu prosseguimento. Apenas em setembro de 2015 a votação fora concluída com a declaração de inconstitucionalidade dos dispositivos legais autorizadores das contribuições de pessoas jurídicas às campanhas eleitorais.

$\mathrm{O}$ artigo tem como objetivo proceder à análise, sob o marco teórico do constitucionalismo democrático, da $\mathrm{ADI}$ n. 4.650, estudando os aspectos jurídicos e sociais presentes na discussão no STF e os seus efeitos possíveis e prognósticos para as eleições futuras e os contornos democráticos do Estado brasileiro, com especial enfoque nas eleições municipais para a Prefeitura do Rio de Janeiro em 2016.

Inicialmente, são introduzidos os aspectos teóricos-conceituais estruturantes do estudo e, logo a seguir, parte-se para a análise das lutas construídas pelos movimentos sociais culminantes para que a Reforma Política fosse compreendida como uma das principais demandas da população brasileira ante o descrédito com a política tradicional. Depois, identificam-se os debates jurídicos sobre a constitucionalidade ou não do financiamento empresarial nas campanhas eleitorais a partir do acompanhamento crítico dos votos dos ministros do STF na ADI n. 4.650 e dos referenciais teóricos por eles utilizados. Por fim, com o cruzamento dos dados obtidos pelo TRE sobre as contas eleitorais das candidaturas à Prefeitura no Rio de Janeiro em 2012 e 2016, são efetuadas críticas dos efeitos da proibição do financiamento empresarial, encaminhando conclusões sobre a temática. 


\section{CONSTITUCIONALISMO DEMOCRÁTICO (POST; SIEGEL): Povo e Corte, Unir aos Separados}

O ponto de referência para fundamentar a avaliação da $\mathrm{ADI}$ n. 4.650 consiste na proposição teórica batizada como constitucionalismo popular na vertente do constitucionalismo democrático, propugnada por Robert Post e Reva Siegel (2013), perfilhada na obra: Constitucionalismo Democrático: por uma reconciliación entre Constitución y Pueblo. ${ }^{3}$

Antes mesmo de sumariamente apresentarmos o pensamento de Post e Siegel, cumpre esclarecer que a aproximação do pensamento constitucional americano não se funda numa atitude de subserviência intelectual provinciana, uma vez que as questões abordadas no constitucionalismo americano têm uma natureza universalista. Os impasses e conflitos tratados por uma perspectiva teórica institucional são transversais em outras sociedades e podem fomentar discussões com aprofundamentos das temáticas relativas ao significado da constituição, ao papel das Cortes Superiores, dentre outros assuntos.

O constitucionalismo democrático é uma forma de abordagem que busca sobrepujar o predomínio do modelo originalista americano, ao coligar uma teoria atenta com a mobilização popular, com as distinções culturais e com uma participação da sociedade civil na qual os compromissos progressistas possam ser expressos por meio da lei, valendo-se dos "founding fathers" sem, todavia, desautorizar novas formas de autoridade constitucional.

Deste modo, insere-se plenamente na própria visão presente no constitucionalismo americano como um gênero maior, no qual o constitucionalismo democrático figuraria como espécie. O estudo do constitucio-

${ }^{3}$ POST, Robert; SIEGEL, Reva. Constitucionalismo democrático: por uma reconciliación entre Constitución y Pueblo. Buenos Aires: Siglo Veintiuno, 2013. 
nalismo americano indica a relevância da percepção da complexidade do fenômeno constitucional e a necessidade de estabelecer conexões entre a teoria institucional e a ciência política, sem, contudo, se ver refém da importação de paradigmas constitucionais e de pensamento ou mesmo a repetição de fórmulas do passado sem o necessário diálogo. Assim, as contribuições da experiência americana são válidas no tratamento de seus "tensionamentos político-constitucionais, em especial, na compreensão da complementariedade entre a teoria constitucional e a ciência política, a fim de construir matrizes teóricas, desenhos e práticas institucionais capazes de se alimentarem da experiência internacional, mas de forma crítica e atenta as singularidades de nossa realidade institucional, política e social.”4

O constitucionalismo popular estaria imerso no debate entre concepções progressistas (defensoras dos juízes como intérpretes da Constituição) e conservadoras (defensoras do originalismo) e, em determinada altura, houve uma reconfiguração das propostas progressistas, passando a incluir a defesa do caráter democrático do constitucionalismo a partir da crítica ao maximalismo da interpretação constitucional (juízes da Suprema Corte Norte-americana responsáveis pela última palavra na interpretação constitucional); outras correntes posicionaram-se pelo minimalismo (juízes e legisladores poderiam influir na interpretação constitucional sem defini-la) e outras, ainda, passaram a defender o constitucionalismo democrático.

Na vertente da democratização do constitucionalismo, Post e Siegel têm sublinhado a simbiótica relação de constante aperfeiçoamento entre a decisão judicial e a sociedade. ${ }^{5}$ Sobressai o processo político-social do

${ }^{4}$ VIEIRA. José Ribas. A centralidade do Constitucionalismo Americano na Teoria Constitucional Contemporânea. Conferência de titularidade do professor doutor José Ribas Vieira, proferida na data de 5/9/2016, na Faculdade Nacional de Direito da Universidade Federal do Rio de Janeiro.

${ }^{5}$ POST, Robert; SIEGEL, Reva. Constitucionalismo democrático: por uma reconciliación entre Constitución y Pueblo. Buenos Aires: Siglo Veintiuno, 2013. p. 43-118. 
backlash ${ }^{6}$ em que a rejeição popular da decisão da jurisdição constitucional, não obstante problemática, tende a provocar o aperfeiçoamento das decisões judiciais e do próprio processo decisório, tendo, por conseguinte, um respeitável efeito positivo para o Poder Judiciário. ${ }^{7}$

De acordo com o constitucionalismo democrático, o Poder Judiciário tem seu lugar na interpretação constitucional, todavia anotam que o sentido do texto constitucional também acontece nas decisões legislativas, nos pronunciamentos da administração pública e nas reivindicações dos movimentos sociais. Haveria um trabalho conjunto entre o Judiciário, os atores políticos e os movimentos sociais para codificar os valores progressistas da constituição.

A legitimidade constitucional está enraizada na sua habilidade para ser reconhecida pelos cidadãos como sua Constituição. Esta perspectiva se sustenta em tradições de ativismo popular autorizadoras dos cidadãos de apresentar clamores sobre o significado da constituição e a opor-se ao governo quando entende que não as respeita. ${ }^{8}$

Segundo Post e Siegel (2013), a Suprema Corte torna-se uma possível colaboradora das instituições democráticas na construção do significado constitucional e na ação catalizadora do constitucionalismo democrático. Defendem que para o Estado de Direito é preciso manter alguma forma de autoridade final dos juízes, pois, em alguns casos, quando há acordo sobre o sentido constitucional, é aceitável um controle judicial forte, e, ainda, que paire uma tensão e conflito entre a supremacia judi-

${ }^{6}$ KLARMAN, Michael. How Brown changed race relations: the backlash thesis. The journal of American history, v. 81, n. 1, 1994.

${ }^{7}$ POST, Robert C. Democracy, expertise, academic freedom: A first amendment jurisprudence for the modern State. New Haven: Yale University Press, 2012. POST, Robert; SIEGEL, Reva. Roe Rage: democratic constitucionalism and backlah. Havard Civil Rights-Civil Liberties Law Review, v. 42, 2007.

${ }^{8}$ POST, Robert; SIEGEL, Reva. Roe Rage: Democratic Constitutionalism and Backlash. Harvard Civil Rights-Civil Liberties Law Review, v. 42, p. 373-433, 2007. 
cial e o constitucionalismo democrático, pois a democracia requer que determinadas condições sejam garantidas pelos juízes com o fim de que os cidadãos possam participar na deliberação.

Os cidadãos, contudo, não têm de aceitar as decisões judiciais como meros sujeitos passivos, pois o debate popular sobre a constituição inspira as memórias e os princípios da tradição constitucional, o que não ocorreria se a cidadania fosse passiva perante as decisões judiciais. Assim, os cidadãos são autores do direito e, deste modo, devem sentir-se, mesmo quando suas concepções sobre constituição diferem da interpretação judicial.

Alguns pontos merecem menção para melhor compreensão do pensamento esboçado por Post e Siegel:

- Legitimidade democrática - a autoridade constitucional depende da sua legitimidade democrática, de sua capacidade para inspirar aos americanos a reconhecê-la como sua constituição. As democracias necessitam de um Estado de Direito forte e com diálogo fluido e contínuo, a fim de evitar, dentre outros problemas, a tirania das maiorias. Os autores alertam que "Acuerdos com amplios apoyos mayoritarios pueden asfixiar una democracia constitucional tanto como um régimen dictatorial." ${ }^{9}$

A opinião pública tem um papel fundamental, pois irá propagar a vontade comum dos significados possíveis do texto constitucional. A legitimidade do texto encontra-se na sociedade. Ao lado da opinião pública há o papel dos movimentos sociais, enquanto instrumentos de alargamento das fronteiras do razoável num determinado período. Em suma, a confiança na Constituição, no seu papel, sua relevância, possibilita aos indivíduos que, muito embora sejam tomadas decisões antagônicas a sua opinião sobre certo tema, acreditem no texto constitucional. Essa crença somente é cabível se o Estado admitir um perene debate sobre o sentido/significado do

${ }_{9}^{9}$ POST, Robert; SIEGEL, Reva. Roe Rage: Democratic Constitutionalism and Backlash. Harvard Civil Rights-Civil Liberties Law Review, v. 42, p. 15, 2007. 
texto promovido pela sociedade. É na possibilidade de discordância que os autores vislumbram a preservação da autoridade constitucional, ou seja, a consciência da seriedade do debate sobre o significado atual do texto jurídico/político é que "irá dar legitimidade a esse mesmo texto. Quando a corte interpreta a constituição de forma desconectada com esse debate, ela transforma o texto em ilegítimo e opressivo e pode causar, com isso, uma ruptura entre a população e sua crença com a autoridade do texto vigente. E é aí que surge o perigo." ${ }^{10}$

O trabalho conjunto entre ramos do poder público e diálogo com movimentos políticos e a opinião pública, confere natureza vinculante na exata medida, contando com a receptividade democrática indispensável para ter legitimidade e efetividade a partir desse diálogo progressivo.

- Movimentos sociais - Post e Siegel entendem que os movimentos sociais conformam o sentido constitucional ao produzir novas percepções aptas a orientar as posturas oficiais. Assim, propõem a superação das descrições tradicionais de como se fazem mudanças constitucionais, pela importância dos movimentos como parte da cultura constitucional.

Cidadãos e governantes podem adotar pontos de vista constitucionais distintos que se equilibrem de modo dinâmico e se condicionem mutuamente. Deste modo, a constituição e a comunidade da qual participam os debatedores, comunicam-se por meio da argumentação, a qual se sujeita às estruturas sociais mediadoras entre emitente e receptor da mensagem. As novas concepções constitucionais precisam de persuasão para se manter, daí recomendar o emprego da linguagem constitucional para estabelecer suas petições e recorrer às tradições do povo a quem se direcionam. Disto resulta o comentário feito de que duas restrições distin-

${ }^{10}$ VIEIRA, José Ribas; DUTRA, Deo Campos. O debate entre originalismo e o constitucionalismo democrático: aspectos atuais da teoria da interpretação constitucional norteamericana. Revista NEJ - Eletrônica, v. 18, n. 1, p. 51-62, jan./abr. 2013. 
guem estes movimentos sociais como criadores de direito constitucional. “La primera es la ‘condición del consentimiento', es decir, no pueden utilizar la coerción sino la persuasión y deben respetar a la autoridad, aunque en algunas ocasiones realicen actividades procedimentales irregulares y disruptivas, e incluso ilegales. En segundo lugar está "la condición de valor público”, pues para convencer a los ciudadanos que no pertenecen a sus filas deben expresar sus valores como valores públicos”. ${ }^{11}$

As reações cidadãs poderiam ter, em muitos casos, efeitos favoráveis no plano da inclusão democrática. Os protestos devem ser concebidos como mecanismos inclusivos democráticos, sobretudo quando subsistem situações crônicas de assimetria de poder. A mobilização a favor ou contra uma decisão é uma forma relevante de compromisso democrático.

O êxito num contexto de progressismo judicial deve ser democraticamente legítimo, tem de refletir os valores e a forma na qual se entende seus profundos significados. Por meio das mobilizações sociais e da expressão das posições políticas pelos grupos não institucionais, as pessoas efetuam demandas concretas sobre o que esperam que seja constitucionalmente amparado ou proibido, sobre a validade que legisladores e juízes devem dar a um significado particular de constituição, e sobre as mudanças que deve ter o direito constitucional para responder a um mundo interconectado e em permanente mudança.

\footnotetext{
${ }^{11}$ NIEMBRO, Roberto O. Una mirada al constitucionalismo popular. Isonomía, n. 38, abr. 2013, p. 191-224. Afirmam ainda que: "De esta manera, conciben a los movimientos sociales como mediadores entre el gobierno y la ciudadanía, permitiendo a los ciudadanos expresar sus inquietudes, críticas o su total resistencia a la política gubernamental. Entre las funciones de los movimientos sociales está la de educar e incitar a la opinión pública para modificar la agenda de las políticas electorales, así como moldear el desarrollo del derecho constitucional. Aunque reconocen que sólo representan a algunas personas y que su informalidad, parcialidad y falta de responsabilidad pública les hace un mal candidato para hablar por el pueblo. De ahí que sólo podrán hablar por todos si tienen éxito y su interpretación es acogida por las autoridades que declaran el contenido del derecho constitucional."
} 
- Ideias, legado, importância do trabalho - um ponto forte do trabalho de Post e Siegel, vem da crítica ao ativismo progressista dos tribunais constitucionais (especialmente Corte de Warren) e o convite à maior sensibilidade para com a sociedade civil organizada. A fundamentação da constituição não apela ao consenso em torno da sua concepção e aplicação. Antes, parte do dissenso que causa intensos intercâmbios dialógicos. A Corte Suprema não deve se afastar destes diálogos, pois a constituição necessita provocar lealdade, muito embora exista desacordo sobre seu significado. A legitimação deve ser democrática e ser representação dos valores sociais, ainda que num contexto de controvérsias culturais.

Para a legitimidade constitucional, os tribunais não devem ter a última palavra ou a única palavra na interpretação constitucional. Eles são uma das vozes, não a única, no diálogo do qual deve surgir o sentido das disposições constitucionais. Assim, haveria uma diferença entre controle judicial de constitucionalidade e supremacia judicial, ou seja, entre a versão do tribunal com a última palavra e o que tenha a única palavra.

O fundamento da legitimidade democrática do constitucionalismo se alicerça em que as decisões surjam não apenas das razões judiciais, mas também das interações entre o poder judicial e outros ramos do poder público, associações civis, partidos políticos, movimentos sociais, centros de investigação, ONGs e o Poder Judiciário em conjunto.

O progressismo do constitucionalismo democrático é dialógico, embora os tribunais tenham pontes entre as normas constitucionais e a realidade social, e devem fazê-las com a consciência da importância da interação com a sociedade civil organizada. A mudança constitucional deve ser dialogada, porque os ramos do poder público devem promover conjuntamente os valores constitucionais progressistas. 
Post y Siegel consideram que “[...] un prerrequisito esencial para una movilización constitucional es el desarrollo de una perspectiva constitucional que resulte lo suficientemente motivadora para el pueblo, así como confiable, para actuar a partir de ella. Esto depende en parte de la capacidad para expresar esa perspectiva constitucional en términos de derecho." 12

Desde então, a mobilização constitucional começa no plano da opinião pública e organização e mobilização sociais. Os argumentos acadêmicos têm a função de simplesmente ajudar a dar forma jurídica aos anseios e às demandas práticas provenientes dessas mobilizações. O relevante, no que concerne aos segmentos profissionais, é que dita formulação jurídica das demandas sociais esteja disponível quando seja necessária.

Em suma, o constitucionalismo democrático está baseado na ideia de que todos devemos participar na configuração do direito constitucional por meio de nossas ações políticas, e outorga de papel central a cidadania na interpretação da Constituição. Assim, manifesta a forma como a sociedade influi, reconstrói e desgasta o valor das decisões judiciais, e impulsiona uma maior participação nas estruturas políticas e econômicas. Também defende uma visão departamentalista do controle da Constituição, segundo a qual nenhum ramo do poder tem o direito de arrogar-se em supremacia sobre outros.

O constitucionalismo democrático não fica isento de críticas a apontar suas deficiências, sobretudo no aspecto operacional das ideias veiculadas. Em que pese à dificuldade em se vislumbrar por quais caminhos operariam os diálogos entre a sociedade, os movimentos sociais e a opinião pública no ofício de interpretação constitucional com as Cortes, é preciso reconhecer uma necessidade de maior abertura nos processos

${ }^{12}$ POST, Robert; SIEGEL, Reva. Roe Rage: Democratic Constitutionalism and Backlash. Harvard Civil Rights-Civil Liberties Law Review, v. 42, p. 32, 2007. 
interpretativos constitucionais, recebendo o dissenso como um ponto positivo numa abordagem democrática que autorizaria, em dados momentos, um papel contramajoritário à Suprema Corte.

A visão positiva sobre o dissenso e a convicção de que ele favorece o diálogo e a democracia no campo da interpretação constitucional, teve especial importância para o enfrentamento dos intensos debates que circularam em torno do financiamento empresarial de campanhas eleitorais. As controvérsias culminaram na interposição pelo Conselho Federal da Ordem dos Advogados do Brasil da Ação Direta de Inconstitucionalidade n. 4.650/2011, no Supremo Tribunal Federal. ${ }^{13}$

A presença do CFOAB serve para ilustrar como é importante abrir o espaço de diálogo para organizações da sociedade civil na interpretação constitucional, imprimindo um caráter democrático aos debates promovidos sobre a polêmica matéria. E ainda que os resultados do julgamento não sejam plenamente satisfatórios aos interesses das organizações demandantes, denotam uma busca por um constitucionalismo democrático, no qual a legitimidade flui de baixo para cima, principalmente nesta situação de financiamento empresarial de campanhas eleitorais, que figura como uma situação crônica de assimetria de poder. Assim, o processo ilustra como os tribunais refletem, mas também constroem a opinião pública.

\footnotetext{
${ }^{13}$ Todo o encaminhamento da Adin é, ele próprio, fruto da ampliação participativa na Constituição de 1988, que incluiu no artigo 103, dentre outros, o CFOAB no rol de legitimados ativos habilitados para ingressarem com ações de controle de constitucionalidade concentrado. Sobre o papel do Conselho Federal da $\mathrm{OAB}$ no controle de constitucionalidade ver: EMERIQUE, Lilian Balmant; LARA, Halison Bruno de Lima. "Sociedade aberta dos intérpretes da Constituição e a participação do Conselho Federal da Ordem dos Advogados do Brasil no controle concentrado de constitucionalidade”. In: Revista do Instituto de Hermenêutica Jurídica, Belo Horizonte: Fórum, ano 13, n. 18, p. 145-170, jul./dez. 2015.
} 


\section{DEMANDA SOCIAL PELA REFORMA POLÍTICA: O Problema do Financiamento Empresarial de Campanhas e as Tentativas Frustradas de Reformas Políticas}

É recorrente em qualquer sociedade democrática a discussão sobre os formatos e as regras do próprio sistema democrático. Isso se deve ao fato de que, a depender do enquadramento institucional, diferentes grupos são beneficiados na sua representatividade política. Toda democracia pode ser vulnerável aos interesses políticos, capazes de utilizar as brechas no enquadramento institucional para perpetuar-se no poder e evitar mudanças que possibilitem retorno à capacidade de escolha legítima à maioria da população.

Dentre os diversos temas apensados no guarda-chuva da Reforma Política, a questão do financiamento das campanhas é uma das que mais possui relevância social e que desperta as maiores polêmicas. É especialmente problemática a relação que as grandes empresas possuem com as eleições. Mesmo não podendo receber votos, quando se excluem as doações feitas pelos próprios candidatos a sua campanha, as doações provenientes de empresas corresponderam a $98 \%$ do total na campanha de $2010 .{ }^{14}$

Nas campanhas eleitorais um maior aporte financeiro significa maior capacidade de produção de material impresso, como panfletos e placas, maior capacidade de contratar institutos/empresas de pesquisa de público e produção de conteúdo de mídia e, sobretudo, a capacidade de contratar equipes de campanha e cabos eleitorais para atingir um maior número de eleitores.

\footnotetext{
${ }^{14}$ Dados colhidos no site “Às Claras”. Disponível em: <www.asclaras.org.br>. Acesso em: 7 maio 2017.
} 
Dessa forma, é criado um movimento no qual as campanhas eleitorais são decididas com cada vez mais recursos financeiros, se tornando, em média, cada vez mais caras. Em seu voto na ADI n. 4.650/2011, o ministro Luiz Fux apresentou que o gasto per capita das eleições no Brasil são maiores, até mesmo, que o de países desenvolvidos.

Segundo dados utilizados por ele, apresentados na audiência pública sobre a $\mathrm{ADI}$ n. 4.650 , se gasta hoje (em dólares) $\$ 10,93$ por pessoa em campanhas eleitorais no nosso país, contra apenas $\$ 2,21$ na Alemanha, $\$ 0,77$ no Reino Unido e irrisórios $\$ 0,45$ na França. Materializando esses dados para a nossa realidade, visualizamos melhor a barreira monetária que deve ser ultrapassada para alguém se eleger no Brasil. Nas eleições de 2010 o custo médio de uma campanha vitoriosa foi de 1,1 milhão de reais para a Câmara de Deputados e 4,5 milhões de reais para o Senado Federal. Já para se tornar governador, o gasto médio foi de 23,1 milhões, e uma campanha presidencial custaria por volta de alarmantes 300 milhões de reais. ${ }^{15}$

Isso tudo se consolida num processo eleitoral enviesado em favor daqueles candidatos que possuem mais recursos, sobretudo provenientes de empresas. Em seu estudo sobre o financiamento empresarial de campanhas, Daniel Sarmento e Aline Osório percebem que existe um prognóstico de as eleições ficarem cada vez mais caras e de os candidatos com maior financiamento serem eleitos. Eles também reforçam a relação construída entre a empresa que financia e o político financiado; " $\mathrm{E}$ dados empíricos revelam que os grandes financiadores de campanhas eleitorais são, na esmagadora maioria dos casos, justamente empresas pertencentes a setores que mantêm estreitas relações com o Poder Público, como a construção civil, o setor financeiro e a indústria." ${ }^{16}$

\footnotetext{
${ }^{15}$ Voto do ministro Luiz Fux na ADI 4.650, proferido em 11/12/13. p. 2. Disponível em: <http://www.stf.jus.br/arquivo/cms/noticiaNoticiaStf/anexo/ADI4650relator.pdf $>$. Acesso em: 7 maio 2017.

${ }^{16}$ SARMENTO, Daniel; OSÓRIO, Aline. Eleições, dinheiro e democracia: a ADI 4.650 e o modelo brasileiro de financiamento de campanhas eleitorais. p. 4. Disponível em: <www. auditoresfiscais.org.br/media/estudos/artigo-adi-4650-362921044.pdf>. Acesso em: 7 maio
} 
Caso ainda mais gritante é a questão das empreiteiras. Essas empresas, muitas vezes, dependem das licitações de obras estatais para atuar e, visando maximizar o seu lucro, fazem doações massivas aos candidatos. Isso é feito para posteriormente garantir contratos e influenciar políticas públicas que as favoreçam. A Operação Lava-Jato ${ }^{17}$ explicitou inúmeras dessas relações espúrias, mas essa é uma padronagem que já era percebida há tempos: segundo dados do portal “Às claras”, em 2012 das dez maiores doadoras para os diretórios partidários seis eram construtoras -e todas as quatro primeiras posições são ocupadas pelas mesmas.

Tabela1 - Maiores doadores (pessoas físicas e empresas) a comitês e diretórios (2012)

\begin{tabular}{|l|l|l|}
\hline Nome & CGC (CNPJ) & Doações \\
\hline Construtora Andrade Gutierrez S.A. & $17.262 .213 / 0001-94$ & $\mathrm{R} \$ 129.238 .341,75$ \\
\hline Construtora Queiroz Galvão S.A. & $33.412 .792 / 0001-60$ & $\mathrm{R} \$ 47.399 .223,68$ \\
\hline Construtora OAS S.A. & $14.310 .577 / 0001-04$ & $\mathrm{R} \$ 43.287 .850,00$ \\
\hline $\begin{array}{l}\text { Construções e Comércio Camargo } \\
\text { Correa S.A. }\end{array}$ & $61.522 .512 / 0001-02$ & $\mathrm{R} \$ 41.885 .443,64$ \\
\hline Vale Fertilizantes S.A. & $33.931 .486 / 0001-30$ & $\mathrm{R} \$ 41.098 .500,08$ \\
\hline $\begin{array}{l}\text { Praiamar Indústria Comércio \& } \\
\text { Distribuição Ltda. }\end{array}$ & $00.851 .567 / 0001-71$ & $\mathrm{R} \$ 31.174 .049,08$ \\
\hline JBS S.A. & $02.916 .265 / 0001-60$ & $\mathrm{R}$ 30.702.926,14 \\
\hline Construtora Norberto Odebrecht S.A. & $15.102 .288 / 0001-82$ & $\mathrm{R} \$ 20.578 .510,01$ \\
\hline Banco BMG AS & $61.186 .680 / 0001-74$ & $\mathrm{R} \$ 18.607 .762,34$ \\
\hline $\begin{array}{l}\text { Carioca Christiani Nielsen } \\
\text { Engenharia S A }\end{array}$ & $40.450 .769 / 0001-26$ & $\mathrm{R} \$ 18.482 .998,30$ \\
\hline
\end{tabular}

Fonte: Dados retirado do site "Às Claras".

Disponível em: <www.asclaras.org.br>. Acesso em: 7 maio 2017.

2017.

${ }^{17}$ Investigação da Polícia Federal comandada judicialmente pelo juiz Sérgio Moro, que iniciou sua fase ostensiva em 17 de março de 2014 para apurar um esquema de lavagem de dinheiro suspeito de movimentar mais de 10 milhões de reais. Com a expansão das investigações descortina-se uma profunda rede de propinas na Petrobrás, que envolvia políticos e empreiteiras ligadas à empresa. 
Os dados reafirmam o impacto do financiamento das empresas tanto no resultado das eleições quanto nas tomadas de decisão por parte do Poder Executivo e Legislativo. A política deixa de ouvir os anseios da população, ser eleito com um programa popular e governar para o povo. Ao invés disso, os políticos passam a pensar a política nacional conforme deseja o lobby das empresas financiadoras de campanha, sustentando um sistema que transforma o poder econômico em poder político e sequestra a representatividade democrática do povo para colocar no poder os representantes dos interesses político-econômicos das empresas.

Em regra, o poder não ousa reformar a si próprio, por isso quase sempre são frustradas as tentativas de reforma política. A primeira tentativa de se proibir o financiamento empresarial de campanhas se deu com o Projeto de Lei n. 2.679 de 2003, que, dentre outras mudanças no sistema político, previa o financiamento exclusivamente público das campanhas eleitorais. ${ }^{18}$ Esse PL foi posteriormente substituído pelo PL n. 1.210, de 2007, quando foram apensadas todas as outras propostas de Reforma Política em tramitação na Câmara dos Deputados. Mesmo com toda a discussão, a Reforma Política não foi votada até o final da legislatura, sendo em 2011 colocada de novo em discussão. Em setembro do mesmo ano a OAB deu entrada no STF com a ADI n. 4.650 arguindo a inconstitucionalidade do financiamento empresarial em campanhas eleitorais, e ganhou o interesse de amplas camadas da sociedade e várias entidades da sociedade civil buscaram participar, seja externamente ao processo, seja internamente, por intermédio das audiências públicas ou como amicus curiae.

\footnotetext{
${ }^{18}$ RABAT, Márcio Nuno. Reforma política: histórico, estágio atual e o lugar da recente proposta do Executivo. p.8-12. Disponível em: <http://bd.camara.gov.br/bd/bitstream/ handle/bdcamara/1385/reforma_politica_rabat.pdf $>$. Acesso em: 7 maio 2017.
} 
O cenário é fundamental para compreender como as demandas populares e as mobilizações organizadas no âmbito da sociedade civil foram fundamentais para a análise dessa demanda pelo STF e como todo esse sentimento foi canalizado em uma $\mathrm{ADI}$ proposta por uma entidade da própria sociedade civil.

\section{ARGUMENTOS JURÍDICOS SOBRE A INCONSTITUCIONALIDADE DO FINANCIAMENTO EMPRESARIAL DE CAMPANHAS POLÍTICAS}

O processo em torno da Ação Direta de Inconstitucionalidade n. 4.650 suscitou amplos debates jurídicos e reacendeu discussões sobre o papel do STF na democracia brasileira e sobre as bases populares do nosso Estado. Tendo por base o voto dos ministros, os textos sobre o tema e a doutrina, se procederá a análise da legislação eleitoral à época da propositura da ADI, o papel do STF enquanto entidade contramajoritária e os principais argumentos utilizados para legitimar a posição majoritária, no caso pela inconstitucionalidade do financiamento de campanhas eleitorais por parte das empresas.

\section{Legislação Brasileira}

Na legislação brasileira o financiamento de campanhas está regulado na Lei n. 9.504/97, conhecida como “Lei das Eleições” e, subsidiariamente, na Lei n. 9.096/96, que trata dos partidos políticos. A Lei n. 13.165/2015, apelidada de "Minirreforma Eleitoral”, foi construída concomitantemente à votação da $\mathrm{ADI}$, sendo sancionada algumas semanas após a conclusão da votação, trazendo modificações à Lei n. 9.504/97. Por meio dessas normas, é constituído um sistema misto de financiamento com a possibilidade de doação, tanto por pessoa física quanto por pessoa jurídica - somados a recursos públicos, como é o caso do fundo partidário. 
No financiamento feito por pessoa física, ficou estipulado um limite de até $10 \%$ do valor bruto declarado no ano anterior ao pleito eleitoral. É válido lembrar que esse teto proporcional à renda garante que certas pessoas tenham o direito a doar mais dinheiro para as candidaturas do que outras, a depender do seu rendimento anual. Já no financiamento por pessoa jurídica, a Lei n. 9.504/9719 autorizava doações de até $2 \%$ do faturamento da empresa no ano anterior à eleição. No caso, apenas as empresas privadas tinham permissão para doar, pois eram vedadas as doações provenientes do estrangeiro, dos órgãos da administração pública, de concessionárias ou permissionárias de serviço público, de entidades sem fins lucrativos (beneficentes, religiosas e desportivas, por exemplo) e de sindicatos.

Esse sistema era muito criticado por gerar enormes distorções e permitir a desigualdade nas eleições, uma vez que, quando utilizado um limite proporcional à capacidade de doação financeira de uma empresa ou de um grande empresário, ficava evidente sua possibilidade financeira infinitamente superior às de um cidadão comum.

\section{Papel do STF}

Uma das grandes questões que a $\mathrm{ADI}$ n. 4.650 suscita, consiste em testar os limites da atuação das Cortes sobre um tema de ordem evidentemente política. Assim, em princípio, não caberia ao Judiciário, com um poder composto por juízes não eleitos, intervir em assunto como a Reforma Política. Isso não significaria, no entanto, que em dados momentos se fizesse necessária a atuação judicial para a garantia de preceitos fundamentais. Em seu voto enquanto relator, o ministro Luiz Fux destaca

${ }^{19}$ Disponível em: <http://www.planalto.gov.br/ccivil_03/leis/L9504.htm>. Acesso em: 7 maio 2017. 
que é preciso uma postura mais incisiva do STF para salvaguardar os pressupostos do regime democrático; “... é dever da Corte Constitucional otimizar e aperfeiçoar o processo democrático, de sorte (i) a corrigir as patologias que desvirtuem o sistema representativo, máxime quando obstruam as vias de expressão e os canais de participação política, e (ii) a proteger os interesses e direitos dos grupos políticos minoritários, cujas demandas dificilmente encontram eco nas deliberações majoritárias.”20

Dessa forma, o argumento utilizado pelo relator da $\mathrm{ADI}$ n. 4.650, e seguido pela parte majoritária do STF, sustenta que, em casos específicos, quando os próprios responsáveis pela matéria em questão estão bloqueando as mudanças por não serem do seu interesse imediato, ou estejam sistematicamente prejudicando uma minoria, seria dever da suprema corte agir para corrigir essa imperfeição. Assim, mesmo com o entendimento de que a Reforma Política é da responsabilidade do Congresso Nacional, se aduz que os mesmos congressistas possuem interesse em manter as regras vigentes pelas quais os próprios foram eleitos. Esse cenário abre um paradoxo em que apenas um ente externo aos interesses em jogo poderia destravar o processo.

É importante ressaltar que, de forma unânime, todos aqueles que argumentaram a favor da intervenção do STF sobre o caso, afirmaram que são necessárias a parcimônia e a compreensão de que a tarefa de constituir a Reforma Política é do Poder Legislativo, cabendo ao Judiciário apenas uma intervenção pontual no que respeita à inconstitucionalidade da norma eleitoral vigente. Isso pode ser observado no voto do relator, ministro Luiz Fux: "Portanto, a atuação da Corte in casu é, precisamente, a de definir se o legislador atuou dentro dessa moldura constitucional,

${ }^{20}$ Voto do ministro Luiz Fux na ADI n. 4.650, proferido em 11/12/13. p. 11. Disponível em: $<$ http://www.stf.jus.br/arquivo/cms/noticiaNoticiaStf/anexo/ADI4650relator.pdf $>$. Acesso em: 7 maio 2017. 
sem a pretensão de substituí-lo, reformulando o modelo de financiamento de campanhas vigentes, o que, aí sim (acredito), violaria o princípio da separação de poderes.”21

Não sem motivos, ao final do julgamento a decisão tomada pelo STF foi apenas de declarar inconstitucional o financiamento empresarial de campanhas, ficando a cargo do legislativo regulamentar o assunto e construir os outros temas da reforma política.

\section{Argumentos Jurídicos da Inconstitucionalidade}

Vários são os argumentos apresentados no julgamento da $\mathrm{ADI}$ n. 4.650 para sustentar a inconstitucionalidade do financiamento empresarial de campanhas eleitorais. Eles se baseiam, principalmente, nos princípios elencados pela constituição como basilares do Estado Democrático de Direito. Destacam-se o princípio democrático, o princípio da igualdade e o princípio republicano.

- Princípio Democrático - o primeiro dos princípios utilizados para robustecer o coro em favor da inconstitucionalidade é o Princípio Democrático. Ele é suporte para todos os outros argumentos ao expressar o povo como fundamento do poder político. $\mathrm{O}$ artigo $1^{\circ} \mathrm{em}$ seu parágrafo único, destaca: "Todo o poder emana do povo, que o exerce por meio de representantes eleitos ou diretamente, nos termos desta Constituição.”22

\footnotetext{
${ }^{21}$ Voto do ministro Luiz Fux na ADI n. 4.650, proferido em 11/12/13. p. 18. Disponível em: $<$ http://www.stf.jus.br/arquivo/cms/noticiaNoticiaStf/anexo/ADI4650relator.pdf $>$. Acesso em: 7 maio 2017.
}

${ }^{22} \mathrm{CRFB} / 88$ - Artigo $1^{\circ}$, Parágrafo Único. 
Dessa forma, compreendendo que a soberania popular é a única base aceita constitucionalmente para o poder político, percebe-se que $o$ financiamento empresarial e sua perversa influência nas campanhas eleitorais está em desacordo com as premissas constitucionais. Se as empresas não votam, tampouco poderiam fazer doações de campanhas.

- Princípio da Igualdade - intimamente aliado ao princípio democrático está o princípio da igualdade. Nele, cada cidadão tem peso igual em uma democracia. Em sua primeira dimensão, o princípio da igualdade serve para garantir o mesmo peso ao voto de cada cidadão.

Vale ressaltar, porém, que a dimensão de igualdade concebida pela Constituição de 1988 não se dá apenas no voto, mas também, dentre outros, na capacidade de influir no processo eleitoral sem distinção de fatores sociais. $\mathrm{O}$ financiamento eleitoral de campanhas permite às empresas influírem de forma decisiva na eleição de muitos candidatos, garantindo representatividade política a uma entidade jurídica que não possui direito ao voto.

A isso se soma a disparidade financeira e a desigualdade de capacidade de doação por parte das empresas, com recursos imensamente superiores à possibilidade dos cidadãos comuns, o que resulta na ampliação dos privilégios no processo de tomadas de decisão política da nação - violação do princípio da igualdade. Esse também é o entendimento de Fux, em seu voto: “... excessiva penetração do poder econômico no processo político compromete esse estado ideal de coisas na medida em que privilegia alguns poucos candidatos - que possuem ligações com os grandes doadores - em detrimento dos demais. Trata-se de um arranjo que 
desequilibra, no momento da competição eleitoral, a igualdade política entre os candidatos, repercutindo, consequentemente, na formação dos quadros representativos." 23

- Princípio Republicano - seguido dos princípios democrático e da isonomia, o princípio republicano é outro potente argumento contrário ao financiamento eleitoral de campanhas pelas empresas. Presente no fundamento do Estado brasileiro, o artigo $1 \square$ trata não apenas da forma de governo, mas também da configuração como a res publica, ou "coisa pública”, deve ser gerida.

Os efeitos do financiamento empresarial de campanhas por parte de empresas chocam-se frontalmente com o princípio republicano. Como vimos, com as doações de campanhas para candidatos que defendem seus interesses, as empresas subvertem a lógica do Estado para benefício próprio.

\section{O QUE MUDOU?}

Análise Empírica do Financiamento nas

Campanhas Eleitorais Para a Prefeitura do Rio de Janeiro em 2012 e 2016

Para analisar a efetividade das mudanças trazidas pela decisão do $\mathrm{STF}$ na $\mathrm{ADI}$ n. 4.650, é fundamental primeiro entender quais foram os pedidos apresentados pelo $\mathrm{CFOAB}$ ao STF e quais deles foram atendidos.

Assim, são elencados três pedidos feitos na propositura da ADI $n$. 4.650: a) a proibição de doações por pessoas jurídicas; b) a criação de um limite uniforme para doações por pessoa física; e c) a adoção de um teto

\footnotetext{
${ }^{23}$ Voto do ministro Luiz Fux na ADI n. 4.650, proferido em 11/12/13. p. 28. Disponível em: $<$ http://www.stf.jus.br/arquivo/cms/noticiaNoticiaStf/anexo/ADI4650relator.pdf $>$. Acesso em: 7 maio 2017.
} 
para uso de recursos próprios dos candidatos em suas campanhas. Dessas, apenas a primeira foi julgada procedente pelo STF, com a declaração de inconstitucionalidade do financiamento empresarial de campanhas por oito votos a três.

A questão central debatida diz respeito aos impactos da ação formulada pelo CFOAB para o fortalecimento da democracia no país. Neste estudo, em razão do enorme montante de dados sobre o financiamento de campanhas das mais variadas candidaturas pelo país inteiro, fez-se a opção de focar a análise nas eleições para a Prefeitura da cidade do Rio de Janeiro com base nos dados colhidos tanto no primeiro turno das eleições de 2012, antes do julgamento, quanto no primeiro turno das eleições de 2016, depois do julgamento da ação.

Como fonte das informações sobre o financiamento das candidaturas, foi utilizada a plataforma de divulgação de contas eleitorais das candidaturas de autoria do Tribunal Superior Eleitoral (TSE).$^{24}$

O objetivo da pesquisa consiste em responder às questões sobre a eficácia real da declaração de inconstitucionalidade do financiamento empresarial de campanhas por parte de empresas e pensar os próximos passos para a busca de um processo eleitoral menos influenciado pelo poder econômico. Para isso, algumas perguntas precisam ser respondidas:

A proibição do financiamento empresarial reduziu o altíssimo gasto médio das campanhas eleitorais ou ocorreu a simples troca do financiamento pela pessoa jurídica das empresas pelo financiamento pela pessoa física dos empresários?

\footnotetext{
${ }^{24}$ Os dados relativos às eleições 2016 foram retirados da plataforma "DivulgaCandContas", disponível em: <http://divulgacandcontas.tse.jus.br/divulga/\#> e os relativos às eleições de 2012 foram retirados da plataforma SPCE WEB, disponível em: <inter01.tse.jus.br/spceweb. consulta.receitasdespesas2012 $>$ e do site $<$ http://www.asclaras.org.br $>$. As consultas foram realizadas no dia 7 maio 2017.
} 
A proibição do financiamento empresarial possibilitou um maior grau de equidade na arrecadação entre os candidatos participantes do pleito?

A proibição do financiamento empresarial contribuiu para desconcentrar o rol de doadores para as campanhas eleitorais?

Antes de proceder a apreciação dos dados, é importante ressaltar algumas das variáveis externas à proibição do financiamento empresarial, que também podem afetar o resultado da investigação para se precaver de eventuais distorções.

A primeira delas é a Minirreforma Eleitoral, promovida pela Lei $n$. 13.165 de 2015, que coloca um teto nos gastos durante a campanha igual a $70 \%$ da última eleição (2012), sendo de 50\% quando houver ocorrido segundo turno. Ela dispõe de uma série de medidas visando a reduzir os custos de campanha. Dentre as principais estão a redução pela metade do calendário eleitoral (que passou de 90 para 45 dias) e a maior regulamentação nos gastos possíveis com materiais de campanha, como placas, bandeiras, etc.

Outro fator importante que foge ao radar do nosso exame são os recursos provenientes de "Caixa dois"; como este não é declarado, o mapeamento nas candidaturas é muito difícil.

Por fim, é também impossível prever os efeitos que a crise econômica brasileira e a Operação Lava-Jato trouxeram sobre a disposição dos doadores no processo eleitoral. Por dedução lógica, em um momento de crise econômica e incerteza financeira a tendência natural é a existência de menos recursos disponíveis para doação. Sobre a Lava-Jato, ela atingiu em cheio boa parte das principais empresas responsáveis pelas doações nas últimas eleições, além de construir um clima negativo para as doações eleitorais, uma vez que os doadores passam a temer que o ocorrido na operação também possa os atingir. 
Com tudo isso em mente, passaremos para a análise dos dados em forma de gráficos para responder às questões elencadas. Para isso, apreciaremos dois principais conjuntos de dados: o montante total de doações para as campanhas e a divisão da arrecadação entre os candidatos.

Nos dados referentes às eleições para a Prefeitura do município do Rio de Janeiro de 2012, foi necessário distinguir os recursos ligados diretamente ao candidato e os recursos ligados ao comitê financeiro, a fim de obter a soma de ambos os dados. Podemos conferir na Tabela a seguir:

Tabela 2 - Doações eleitorais por candidato nas eleições de 2012 à Prefeitura do Rio de Janeiro

\begin{tabular}{|c|c|c|c|}
\hline Candidato & $\begin{array}{l}\text { Recursos do } \\
\text { Candidato }\end{array}$ & $\begin{array}{l}\text { Recursos do } \\
\text { Comitê }\end{array}$ & $\begin{array}{l}\text { Total de } \\
\text { Recursos }\end{array}$ \\
\hline $\begin{array}{l}\text { Eduardo da Costa Paes } \\
\text { (PMDB) }\end{array}$ & $\mathrm{R} \$ 21.208 .741,10$ & $\mathrm{RS} 18.425 .790,69$ & $\mathrm{R} \$ 39.634 .531,79$ \\
\hline $\begin{array}{l}\text { Rodrigo Felinto Ibarra Epitácio } \\
\text { Maia (DEM) }\end{array}$ & $\mathrm{R} \$ 6.400 .000,00$ & $\mathrm{R} \$ \mathbf{7 0 . 0 0 0 , 0 0}$ & $\mathrm{R} \$ 6.470 .000,00$ \\
\hline $\begin{array}{l}\text { Aspásia Brasileiro Alcântara de } \\
\text { Camargo (PV) }\end{array}$ & $\mathrm{R} \$ 115.829,68$ & $\mathrm{R} \$ 2.606 .490,32$ & $\mathrm{R} \$ 2.722 .320,00$ \\
\hline $\begin{array}{l}\text { Otavio Santos da Silva Leite } \\
\text { (PSDB) }\end{array}$ & $\mathrm{R} \$ 1.523 .189,00$ & $\mathrm{R} \$ 170.000,00$ & $\mathrm{R} \$ 1.693 .189,00$ \\
\hline $\begin{array}{l}\text { Marcelo Ribeiro Freixo } \\
\text { (PSOL) }\end{array}$ & $\mathrm{R} \$ 1.009 .071,22$ & $\mathrm{RS} 156.302,00$ & $\mathrm{R} \$ 1.165 .373,22$ \\
\hline Cyro Garcia (PSTU) & $\mathrm{R} \$ \mathbf{3} 32.188,49$ & $\mathrm{R} \$$ 61.873,23 & $\mathrm{R} \$ 94.061,72$ \\
\hline Fernando Leite Siqueira (PPL) & $\mathrm{R} \$ \mathbf{S}^{4} .299,00$ & $\mathrm{R} \$ 0,00$ & $\mathrm{RS} 45.299,00$ \\
\hline Antonio Carlos Silva (PCO) & $\mathrm{R} \$ 2.000,00$ & $\mathrm{R} \$ \mathbf{S} 0,00$ & $\mathrm{R} \$ 2.000,00$ \\
\hline Soma total de recursos & $\mathrm{R} \$$ 30.336.318,49 & $\mathrm{R} \$ 21.490 .456,24$ & $\mathrm{RS} 51.826 .774,73$ \\
\hline
\end{tabular}

Fonte: Dados retirados do site: <http://www.asclaras.org.br>. Acesso em: 7 maio 2017.

Na campanha de 2016 foi eliminado o campo "Recursos do Comitê", porque essa distinção não era mais necessária, posto que, com a extinção do comitê financeiro, o próprio candidato precisou declarar as doações recebidas de seu partido. 
Tabela 3 - Doações eleitorais por candidato nas eleições de 2016 à Prefeitura do Rio de Janeiro

\begin{tabular}{|l|r|}
\hline Candidato & Total de Recursos \\
\hline Alessandro Molon (Rede) & $\mathrm{R} \$ 614.527,14$ \\
\hline Carmen Migueles (Novo) & $\mathrm{R} \$ 41.270,98$ \\
\hline Marcelo Crivella (PRB) & $\mathrm{R} \$ 9.664 .174,81$ \\
\hline Cyro Garcia (PSTU) & $\mathrm{R} \$ 20.137,01$ \\
\hline Flávio Bolsonaro (PSC) & $\mathrm{R} \$ 1.166 .1598,13$ \\
\hline Indio da Costa (PSD) & $\mathrm{R} \$ 474.568,00$ \\
\hline Jandira Feghali (PCdoB) & $\mathrm{R} \$ 2.029 .585,59$ \\
\hline Marcelo Freixo (PSOL) & $\mathrm{R} \$ 1.448 .114,00$ \\
\hline Carlos Osório (PSDB) & $\mathrm{R} \$ 9.223 .254,27$ \\
\hline Pedro Paulo (PMDB) & $\mathrm{R} \$ 0,00$ \\
\hline Thelma Bastos (PCO) & $\mathrm{R} \$ 25.553 .489,43$ \\
\hline Soma total de recursos &
\end{tabular}

Fonte: Dados retirados do portal <http://divulgacandcontas.tse.jus.br/ divulga/>. Acesso em: 7 maio 2017.

A partir da análise destes dados é possível chegar a algumas conclusões. Primeiramente, o montante total de recursos reduziu significantemente de 2012 para 2016. Se na primeira eleição foram gastos RS $51.826 .774,73$, na segunda houve uma redução de mais de $50 \%$, para $R \$$ 25.553.489,43. Ressalte-se que nas eleições de 2016 nem mesmo o teto de gastos estabelecido pela Lei n. 13.165/2015 foi alcançado. Em realidade, nenhum dos candidatos sequer chegou perto de arrecadar o valor de RS 19.858.352,08 (estabelecido como limite de gastos). Os dois candidatos que mais arrecadaram foram Marcelo Crivella, com R\$ 9.664.174,80, e Pedro Paulo, com R\$ 9.223.254,27, ambos com menos da metade do teto de gastos.

Se a redução no montante total dos gastos é facilmente perceptível, é muito mais difícil analisar se houve uma democratização na repartição da arrecadação, ou seja, se as disparidades de arrecadação entre os candidatos diminuíram. Os dois Gráficos a seguir comparam a porcentagem por candidato em 2012 e 2016. 
Gráfico 1 - Distribuição de recursos nas eleições de 2012

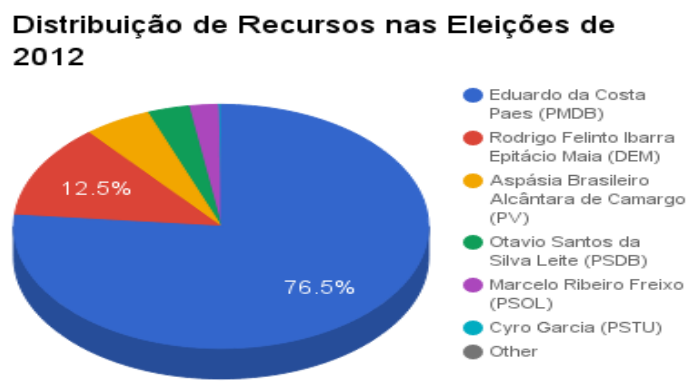

Fonte: Disponível em: <http://divulgacandcontas.tse.jus.br/divulga/> . Acesso em: 7 maio 2017.

Gráfico 2 - Distribuição de recursos nas eleições de 2016

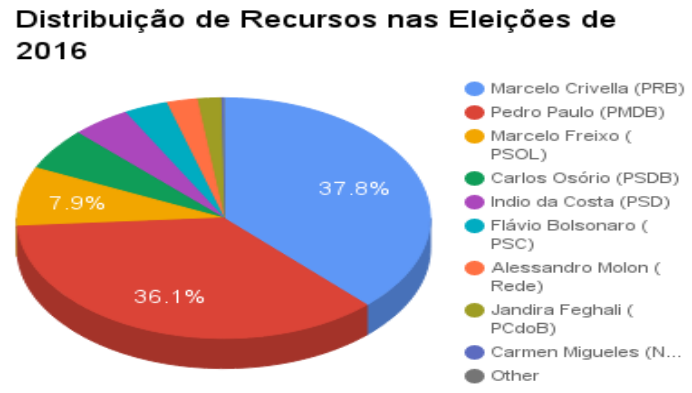

Fonte: Disponível em: <http://divulgacandcontas.tse.jus.br/divulga $>$. Acesso em: 7 maio 2017.

A partir da comparação dos dois gráficos podemos perceber que, em 2016, apesar de ainda manter-se uma concentração dos recursos em torno de dois candidatos (Marcelo Crivella - PRB - com 37,8\% e Pedro Paulo - PMDB - com 36,1\%), existe muito mais pluralidade de financia- 
mento do que no ano de 2012, quando um só candidato (Eduardo Paes - PMDB -, posteriormente reeleito prefeito) arrecadou 76,5\% do total de recursos utilizados nas eleições.

Chama atenção o fato de que grande parte da arrecadação dos candidatos provém de transferências feitas por seus partidos; o que pode significar uma maior importância do Fundo Partidário, mas também que muitos doadores preferem dar dinheiro para os partidos ao invés de se envolver diretamente com a campanha do candidato em questão - para não vincular sua imagem ou se proteger de possíveis escândalos.

No caso das candidaturas do Rio de Janeiro, Pedro Paulo teve uma quantia de RS 3.637.749,81 doados pelo Diretório Regional do seu partido (PMDB). Esse número representa um valor de 39,44\% do total de recursos arrecadados pela sua campanha, que somaram o montante de RS 9.223.254,27. Não obstante, adicionam-se a esse valor do diretório estadual do PMDB mais 10,12\% provenientes do diretório municipal, 2,27\% do diretório nacional e até mesmo recursos de partidos aliados, como 4,44\% do diretório municipal do Partido Trabalhista Brasileiro (PTB). Como máxima dessa tendência, o candidato vitorioso nas urnas, Marcelo Crivella, teve nada menos que 97,27\% dos seus $\mathrm{R} \$$ 9.664.174,81 doados pelo Partido Republicano Brasileiro (PRB). Boa parte desses recursos é proveniente do fundo partidário.

Outro exame importante a ser feito é a diferença entre a concentração das doações a cada candidato, visando a entender se o fim da doação por parte das empresas possibilita o florescimento de uma maior pluralidade de doadores ou se a única mudança seria aquela na qual, ao invés das empresas, os empresários continuariam concentrando o monopólio das doações.

Em um diagnóstico realizado ainda no início do processo eleitoral pela Diretoria de Análise de Políticas Públicas da Fundação Getúlio Vargas (DAPP/FGV), sob encomenda do jornal $O$ Globo, foram cruzados os CPFs 
dos doadores para as candidaturas a prefeito do Rio de Janeiro com os CNPJs das empresas ativas. Os resultados, ainda que preliminares, uma vez que a pesquisa fora efetuada antes de se encerrar o prazo para mais doações, são alarmantes; "Do conjunto de doadores dos candidatos a prefeito do Rio, 59 deles doaram, cada um, mais de R\$ 30 mil. Só um deles não é ligado a nenhuma empresa. Todos os outros 58 desse grupo têm altos cargos em companhias - como sócio, diretor, administrador ou presidente. Somados, representam um total de 643 empresas, a maior parte do setor de construção e engenharia.” ${ }^{25}$

Esses dados significam que, ainda que o gasto total de campanhas tenha diminuído e o financiamento tenha sido distribuído de forma menos desigual que em 2012, o obstáculo central do financiamento de campanhas por parte de empresas ainda não foi totalmente resolvido. Com a declaração de inconstitucionalidade do financiamento empresarial, os empresários passaram a doar enquanto pessoa física e continuam dominando o cenário como principais doadores.

A pesquisa ainda conclui que as empreiteiras, que já eram identificadas nas eleições passadas como um problema por serem as principais financiadoras e construírem íntimas e obscuras relações com o poder estatal, continuam constituindo as maiores doações. Nos dados da pesquisa, 259 das empresas doadoras são do ramo de engenharia e construção, somadas a 129 do ramo imobiliário. Juntas, elas correspondem a cerca de 60\% das empresas doadoras. Reforça-se, ainda, que entre os empresários a concentração é a regra. Na pesquisa, dos 59 doadores, 54 tinham como destino a campanha do candidato Pedro Paulo (PMDB). Vale ressaltar

${ }^{25}$ DUARTE, Alessandra. Empresas driblam lei para doar a campanhas eleitorais. Disponível em: <http://hdl.handle.net/10438/17168>. Acesso em: 7 maio 2017. 
que Pedro Paulo é o candidato de sucessão à atual Prefeitura e muitos dos empresários doadores possuem vínculos em empreendimentos com a gestão.

Não obstante, em que pese a continuação dos grandes financiadores, a campanha de 2016, também favoreceu o surgimento do financiamento de massas, pelo qual os candidatos apelam para estratégias de crowdfunding para receber pequenas doações de uma grande quantidade de pessoas e atingir uma ampla soma total de valores. A campanha do candidato Marcelo Freixo (PSOL), que ficou em segundo lugar nas eleições, foi marcada por uma expressiva campanha de doações.

Mediante o site <https://eufinancio.marcelofreixo.com.br/> o candidato obteve 1,8 milhões de reais com doações de 14.027 pessoas, uma grande explosão de doações, que garantiram a maior parte dos recursos da sua campanha. Note-se que, apesar da enorme quantidade de doadores, a campanha de Freixo ainda obteve apenas cerca de $1 / 5$ do que as maiores campanhas obtiveram em recursos - tanto Pedro Paulo quanto Marcelo Crivella passaram dos R\$ 9.000.000,00. Outros candidatos, como Jandira Feghali e Alessandro Molon também buscaram experiências de financiamento coletivo, mas sem o enorme sucesso alcançado pelo candidato do PSOL. A experiência com financiamento coletivo demonstra caminhos possíveis para um financiamento eleitoral mais plural e igualitário entre os candidatos, mas ainda se revela insuficiente para se contrapor aos recursos provenientes de grandes empresários nas campanhas eleitorais.

Um instrumento importante para avaliar o peso dos grandes doadores é realizar o cálculo da doação média de cada candidato, dividindo o total de recursos pelo total de doações. Assim, é possível analisar as diferenças no perfil econômico dos doadores de cada candidato e perceber se a influência das doações continua concentrada em poucos doadores ou se espalha para uma grande quantidade dos mesmos. 
Tabela 4 - Doação Média dos Candidatos à Prefeitura do Rio de Janeiro nas Eleições de 2016

\begin{tabular}{|c|c|c|c|}
\hline Candidato & \begin{tabular}{|l|} 
Total de \\
Recursos \\
\end{tabular} & $\begin{array}{l}\text { Total de } \\
\text { Doações }\end{array}$ & Doação Média \\
\hline Alessandro Molon (Rede) & $\mathrm{RS}$ 614.527,14 & 78 & $\mathrm{R} \$ \mathrm{7} 7.878,55$ \\
\hline Carmen Migueles (Novo) & $\mathrm{R} \$ 41.270,98$ & 31 & $\mathrm{R} \$ 1.331,32$ \\
\hline Marcelo Crivella (PRB) & RŞ 9.664.174,81 & 103 & $\mathrm{R} \$ 93.826,93$ \\
\hline Cyro Garcia (PSTU) & $\mathrm{R} \$ 20.137,01$ & 30 & $\mathrm{R} \$ 671,23$ \\
\hline Flávio Bolsonaro (PSC) & $\mathrm{R} \$ \mathrm{~s} 81.698,13$ & 12 & $\mathrm{R} \$ \mathbf{7 2 . 6 4 1 , 5 1}$ \\
\hline Índio da Costa (PSD) & $\mathrm{R} \$ \mathrm{~S} 1.166 .159,00$ & 27 & $\mathrm{R} \$ 43.191,07$ \\
\hline Jandira Feghali (PCdoB) & $\mathrm{R} \$ 474.568,50$ & 328 & $\mathrm{R} \$ 1.446,85$ \\
\hline Marcelo Freixo (PSOL) & $\mathrm{R} \$ 2.029 .585,59$ & 17.859 & $\mathrm{R} \$ 113,64$ \\
\hline Carlos Osório (PSDB) & $\mathrm{R} \$ 1.448 .114,00$ & 62 & $\mathrm{R} \$ 23.356,67$ \\
\hline Pedro Paulo (PMDB) & $\mathrm{R} \$ 9.223 .254,27$ & 2.710 & $\mathrm{R} \$ 3.403,41$ \\
\hline Thelma Bastos (PCO) & $\mathrm{R} \$ 0,00$ & 0 & 0 \\
\hline Soma total de recursos & $\mathrm{R} \$ 25.553 .489,43$ & 21.240 & $\mathrm{R} \$ 1.203,08$ \\
\hline
\end{tabular}

Fonte: Disponível em: <http://divulgacandcontas.tse.jus.br/divulga/>. Acesso em: 7 maio 2017.

A Tabela demonstra como existe uma grande variação entre as doações médias dos candidatos. Enquanto Carmen Migueles, Cyro Garcia, Jandira Feghali e Marcelo Freixo possuem doações médias, que são inferiores ou se aproximam da média geral, outros candidatos, como Alessandro Molon, Marcelo Crivella, Flávio Bolsonaro, Índio da Costa, Carlos Osório e Pedro Paulo, possuem médias muito superiores à geral.

É importante, no entanto, fazer uma ressalva em razão de certos candidatos muito dependentes do fundo partidário. Alguns deles receberam recursos quase que unicamente de seus próprios partidos, o que significa poucas doações com muitos recursos, mas sem influência de empresas. Esse é o caso de Marcelo Crivella, que recebeu 97\% do seu valor arrecadado do seu partido (PRB) e de Flávio Bolsonaro, que, das 12 doações recebidas, apenas uma não veio do seu partido (míseros RS 11,63 doados pelo Pastor Everaldo Dias Pereira, ex-candidato presidencial 
do Partido). Ambos são os dois candidatos com as doações mais concentradas. Outros candidatos com grande centralização também possuem muitas doações feitas pelos partidos que os apoiavam, como é o caso de Alessandro Molon, Índio da Costa e Pedro Paulo. Todos com o seu respectivo Partido como o principal doador de campanha.

Um caso interessante é o do candidato Osório. O maior doador da sua campanha é o próprio candidato, com R\$ 405.014,00 doados por ele, que correspondem a $27,97 \%$ do total de doações. Isso abre margem para um debate futuro sobre os limites do autofinanciamento em campanhas e da necessidade de restrição para evitar que um candidato milionário tenha muito mais capacidade eleitoral que os demais.

\section{CONCLUSÃO}

O olhar otimista sobre o dissenso e a percepção dele como um instrumento para o diálogo e a democracia no campo da interpretação constitucional (POST; SIEGEL, 2013), mostraram-se relevantes para o enfrentamento dos acalorados debates sobre o financiamento empresarial de campanhas eleitorais. As disputas afluíram para a decisão da interposição pelo CFOAB da ADI n. 4.650/2011, no STF.

A litigância resultante da ação movida pelo $\mathrm{CFOAB}$ serve para ilustrar como é importante abrir o espaço de diálogo para organizações da sociedade civil na interpretação constitucional, produzindo um estilo democrático nas questões promovidas sobre a polêmica matéria. Os resultados do julgamento denotam uma busca por um constitucionalismo democrático, em que a legitimidade flui de baixo para cima. Assim, o processo ilustra como os tribunais refletem e também constroem a opinião pública.

O presente estudo revela que o financiamento empresarial de campanhas traz graves danos para o processo eleitoral ao promover a desigualdade entre as candidaturas e construir uma cultura de captura do poder 
estatal pelo interesse de empresas privadas. Tudo isso leva à constituição de relações não republicanas entre capital e Estado, como aquelas derivadas das empresas investindo dinheiro em campanhas eleitorais para maximizar seus lucros, por intermédio de legislação favorável e, no caso das empreiteiras, garantias de contratos com a nova gestão.

A ADI n. 4.650 possibilitou o questionamento das estruturas de financiamento eleitoral existente na Constituição, e o STF agiu de forma a deslanchar um debate nitidamente travado por maiorias congressuais que, em defesa do seu próprio interesse, mantinham um sistema profundamente danoso à democracia. $\mathrm{O}$ financiamento de empresas para campanhas eleitorais é inconstitucional por romper com os princípios democráticos, posto que as empresas não são sujeitos políticos, igualitários, pois geram desigualdade na intervenção política entre os cidadãos e republicanos, pela criação de relações de captura dos bens e ações públicos para o lucro e interesse de agentes privados.

Após a decisão do STF de proibir o financiamento empresarial de campanhas, é possível notar, ao menos nas eleições à Prefeitura do Rio de Janeiro, uma relação correlata de redução do montante total dos recursos, menor desigualdade entre os candidatos e maior peso de pequenas doações individuais nas campanhas. Uma tendência importante a ser observada é o aumento de seriedade do fundo partidário com as limitações às doações empresariais, uma vez que muitos candidatos foram quase que inteiramente financiados pelos recursos dos seus próprios partidos.

No período entre a finalização da $\mathrm{ADI}$ n. 4.650 e as eleições de 2016, foi sancionada a Lei n. 13.165/2015, e a Operação Lava-Jato entrou em ápice e o país adentrou em um grave processo de crise econômica. Esses processos também podem ter contribuído para o quadro apresentado nas eleições municipais. Em virtude disso, maiores investigações sobre o tema são necessárias para observar uma relação direta de causalidade. Os dados de outras cidades precisam ser analisados e seria importante 
também observar as eleições para os cargos do Legislativo. É importante notar também como essas novas regras vão interferir nas eleições gerais de 2018 , tendo em vista que uma campanha para presidente, governador, senador ou deputado possui grandes diferenças em relação a uma campanha municipal.

Apesar dos avanços apontados pela análise dos dados, os gastos eleitorais continuam muito altos e as relações de doação por pessoa física continuam desiguais, uma vez que os empresários seguem doando vastas somas e contribuindo decisivamente para que certos candidatos tenham um maior volume de recursos do que os outros. Em suma, são positivos os avanços recentes em matéria de reforma eleitoral; entretanto a luta por mais democracia e um sistema que não seja vulnerável aos interesses dos mais ricos e poderosos ainda é e será extensa. Cumpre aos movimentos sociais, à sociedade civil organizada e aos operadores do Direito, travar essa constante batalha e construir uma sociedade mais justa.

\section{REFERÊNCIAS}

ABRAMO, Cláudio Werner. Poder econômico e financiamento eleitoral no Brasil - Parte 2: concentração e efetividade das doações privadas. Disponível: <excelencias.org.br/docs/financia_desigualdade.pdf $>$. Acesso em: 7 maio 2017.

BARROSO, Luís Roberto. Curso de Direito Constitucional Contemporâneo. 5. ed. São Paulo: Saraiva, 2015.

. O controle de constitucionalidade no direito brasileiro. 6. ed. São Paulo: Saraiva, 2012.

DUARTE, Alessandra. Empresas driblam lei para doar a campanhas eleitorais. Disponível em: <http://hdl.handle.net/10438/17168>. Acesso em: 7 maio 2017. 
DWORKIN. Ronald. The Devastating Decision. The New York Times Review of Books, 25 fev. 2010. Disponível em: <http://www.public.iastate.edu/ jwcwolf/ Law/DworkinCitizensUnited.pdf $>$. Acesso em: 20 abr. 2017.

EMERIQUE, Lilian Balmant; LARA, Halison Bruno de Lima. Sociedade aberta dos intérpretes da Constituição e a participação do Conselho Federal da Ordem dos Advogados do Brasil no controle concentrado de constitucionalidade. In: Revista do Instituto de Hermenêutica Jurídica, Belo Horizonte: Fórum, ano 13, n. 18, p. 145-170, jul./dez. 2015.

KLARMAN, Michael. How Brown changed race relations: the backlash thesis. The journal of American History, v. 81, n. 1, 1994.

NIEMBRO, Roberto O. Una mirada al constitucionalismo popular. Isonomía, n. 38, p. 191-224, abr. 2013.

NICOLAU, Jairo Marconi. Sistemas eleitorais. 6. ed. São Paulo: FGV, 2012. . Eleições no Brasil - do Império aos dias atuais. Rio de Janeiro: Zahar, 2012.

POST, Robert; SIEGEL, Reva. Constitucionalismo democrático: por una reconciliación entre Constitución y Pueblo. Buenos Aires: Siglo Veintiuno, 2013. . Roe Rage: Democratic Constitutionalism and Backlash. Harvard Civil Rights-Civil Liberties Law Review, v. 42, p. 373-433, 2007.

POST, Robert C. Democracy, expertise, academic freedom: A first amendment jurisprudence for the modern State. New Haven: Yale University Press, 2012. RABAT, Márcio Nuno. Reforma política: histórico, estágio atual e o lugar da recente proposta do Executivo. Disponível em: $<$ http://bd.camara.gov.br/bd/ bitstream/handle/bdcamara/1385/reforma_politica_rabat.pdf>. Acesso em: 7 maio 2017.

SARMENTO, Daniel; OSÓRIO, Aline. Eleições, dinheiro e democracia: a $\mathrm{ADI} 4.650$ e o modelo brasileiro de financiamento de campanhas eleitorais. Disponível em: <www.auditoresfiscais.org.br/media/estudos/artigo-adi-4650-362921044.pdf $>$. Acesso em: 7 maio 2017. 
VIEIRA, José Ribas; DUTRA, Deo Campos. O debate entre originalismo e o constitucionalismo democrático: aspectos atuais da teoria da interpretação constitucional norteamericana. Revista NEJ - Eletrônica, v. 18, n. 1, p. 51-62, jan./abr. 2013.

VIEIRA, José Ribas. A centralidade do Constitucionalismo Americano na Teoria Constitucional Contemporânea. Conferência de Titularidade do Prof. Dr. José Ribas Vieira, proferida na data de 5/9/2016, na Faculdade Nacional de Direito da Universidade Federal do Rio de Janeiro. 